\title{
Compositionality without word boundaries: (the) more and (the) most ${ }^{1}$
}

\author{
Anna Szabolcsi \\ New York University
}

\begin{abstract}
This paper seeks to illustrate the advantages of not treating phonological words as distinguished building blocks in compositional semantics. Following Bobaljik 2012, we derive the relative readings of amount superlatives in two steps, [[[d-many] comparative] superlative]. The existence of two comparative constructions is revealed, involving more vs. the more. Each builds a different superlative construction, explaining the conflicting intuitions about superlatives in the literature, as well as puzzles relating to the definite article in superlatives.
\end{abstract}

Keywords: comparative, superlative, relative reading, proportional, focus

\section{Introduction}

The principle of compositionality says that the meaning of a complex expression is a function of the meanings of its parts and how they are put together. What are the "parts"? This question can be asked in many ways. Surface constituents? LF constituents? Only audible parts? Also phonetically empty ones? What about type shifters? The version of the question the present paper addresses is this:

(1) Are phonological words necessarily parts, even minimal (primitive) parts, that a compositional grammar should take into account?

As a rule of thumb, semanticists typically take words to be the building blocks of compositional analyses. But various recent theories have converged on the view that words are not distinguished building blocks in morphology and syntax. One such theory is Distributed Morphology (Halle \& Marantz 1994; Embick 2010; and others). The assumptions of hierarchical syntactic structure all the way down to roots and Late Insertion of vocabulary items are the most pertinent. As

\footnotetext{
${ }^{1}$ I thank Chris Barker, Lucas Champollion, and the audiences at SALT 22 and at UCLA for discussion.
} 
Harley (2012) explains, on these assumptions the typological differences between polysynthetic and isolating languages do not require the postulation of radically different mechanisms in UG, and the phonological word has no special status in semantic interpretation. Then, some versions of Minimalist syntax conclude that phonological words may correspond to large chunks of syntactic structure (Koopman \& Szabolcsi 2000; Julien 2002; Sigurðsson 2004; Koopman 2005; Kayne 2005, 2010; Starke 2009; and others). The structures they postulate differ from those of Distributed Morphology, but they are similar in that word boundaries are argued to play no role.

If no demarcation line corresponds to word boundaries in morphology and syntax, then word boundaries are not expected to be either upper bounds or lower bounds for compositional semantics. No lower bounds means that words are not compositional primitives: complex meanings cannot be simply written into the lexical entries, without asking how the parts of the word contribute to them. No upper bounds means that a part of a word may reach out to operate on the rest of the sentence.

In formal semantics, the poster child for the "no word boundaries" approach is amount superlative most (Heim 1985, 2000; Hackl 2009). The present paper takes up this case and hopes to reap further benefits by pursuing the same approach even more vigorously.

Based on cross-linguistic evidence from suppletive morphology, Bobaljik (2012) hypothesizes that the representation of the superlative properly contains that of the comparative. I show that building the semantics in two steps, i.e. as $[[[d$-many $]$ comparative $]$ superlative $]$, sheds new light on why there are two robustly different intuitions about the semantics of so-called relative superlatives in the literature. The debate concerns what comparison is made in sentences like (2).

Who climbed the most/fewest mountains?

On one analysis (Heim 2000; Hackl 2009), climbers are compared with respect to their achievements. On another analysis (Farkas \& Kiss 2000; Sharvit \& Stateva 2002; Krasikova 2011), numbers of mountains are compared. I will argue that there are two distinct comparative constructions out of which superlatives are built, and the two analyses correlate with this duality. The results are truthconditionally equivalent, which explains why the debate came to something of an impasse. But they are not equivalent morpho-syntactically, and they are not equal in offering an insight into why a superficially definite noun phrase notoriously patterns with indefinites. Furthermore, if the hypothesis of Transparent Interfaces is correct (Hackl 2009; Lidz et al. 2011), they predict different processing strategies. The approach I am pursuing aligns with those that hold that the task of compositional semantics does not end with producing the correct truth conditions. 
Compositionality without word boundaries

In the same decompositional spirit but treading a less beaten path, Szabolcsi 2010: §12 and Szabolcsi, Whang \& Zu 2012 explore the composition of quantifier words in Chinese, Hungarian, Japanese, and other languages. It is well-known from the typological literature that the cross-linguistic counterparts of someone and everyone contain particles that function elsewhere as disjunctions, question markers, existential verbs, conjunctions, additive and scalar particles, and so on. In the above-mentioned work and in ongoing research I propose that Boolean semantics and the semantics of alternatives promise to be useful in explicating the relationship among these particles.

\section{Background: Superlatives}

To recap, adjectival superlatives have two kinds of interpretations: ${ }^{2}$

(3) Who expects to climb the tallest mountain?

Absolute, ABS 'Who expects to climb the mountain that is taller than any other mountain [in the area]?'

Relative (downstairs), REL1 'Who expects to climb a taller mountain than how tall a mountain anyone else climbs?'

Relative (upstairs), REL2 'Who expects to climb a taller mountain than how tall a mountain anyone else expects to climb?'

Heim (1985, 2000), Szabolcsi (1986), Hackl (2009), and others proposed that in ABS, -est has DP-internal scope, whereas in REL, -est has sentential scope. The latter clearly calls for setting aside word boundaries.

The amount expression most is also a superlative: many-est. Like tallest, most and fewest have relative readings:

\footnotetext{
${ }^{2}$ Heim (1999) raised the question whether ABS and REL constitute two different readings, or just follow from two ways of picking the contextually relevant sets of mountains. Heim herself supported the "two readings" view, with reference to so-called upstairs de dicto readings, which cannot be obtained by context setting, but the issue reverberated in the literature. REL2 in (3) is an instance of the upstairs de dicto reading. I wish to point out that amount superlatives are similar to the upstairs de dicto reading of adjectival superlatives in that they cannot be obtained using the "one reading - different contexts" approach, because they are concerned with pure degrees. The subject matter of the present paper is amount superlatives, so this controversy does not concern us. It may be noted though that, according to Aihara 2009 and Cinque 2010: 12, Japanese and Italian syntactically distinguish ABS and (clause-internal, de re) REL even in adjectival superlatives, which would be surprising if the distinction in that domain were merely contextual.
} 
(4) Who expects to climb the most/fewest mountains? 'more/fewer than anyone else (expects to) climb(s)'

Like tallest, most has an absolute reading. This, Hackl (2009) argues, is equivalent to the classical proportional reading:

$$
\text { Most (of the) men snore }=\mid \text { men } \cap \text { snore }|>| \text { men } \cap \text { not snore } \mid
$$

The following example illustrates the difference between the absolute, majority reading (most [of the]) and the relative, plurality reading (the most):

(6) In the original system, the candidate who received both the most votes and more than half of all votes cast [i.e. most of the votes, AS] would become President, the candidate receiving the second most votes would become Vice President. http://en.wikipedia.org/wiki/Electoral_College_(United_States)

But fewest [of the] has no absolute reading:

* Fewest (of the) men snore.

Hackl points out that a decompositional analysis can explain these facts, but one that takes most and fewest to be lexical primitives can only stipulate them. Supplementing Heim's (2000) semantics with an innovative approach to absolute most, he builds both readings from the pieces below. Like Heim, he adjoins [est $C]$ to VP to obtain the relative reading, and to NP to obtain the absolute reading.

$\operatorname{many}(d)(P)=\lambda x[P(x) \wedge|x| \geq d]$ 'the set of pluralities $x$ with a property (e.g. mountains) and with cardinality at least $d$ '

(9) If defined, -est $(C)(B)(x)$ is true iff $\forall \mathrm{y}[(\mathrm{y} \in \mathrm{C} \wedge \mathrm{y} \neq \mathrm{x}) \rightarrow \max \{\mathrm{d}: \mathrm{B}(\mathrm{d})(\mathrm{x})\}>\max \{\mathrm{d}: \mathrm{B}(\mathrm{d})(\mathrm{y})\}]$ 'in the set $C$ of pluralities, $x$ has a greater degree of $B$-ness than any $y \neq x$ ' -est $(C)(B)(x)$ is defined iff $x$ has an alternative in the context set $C$ of things with some degree of $B$-ness.

More precisely, Hackl (2009) does not address the English distinction between most of the mountains and the most mountains, and discusses German instead, a language with a single ambiguous form, die meisten Berge. 
Compositionality without word boundaries

\section{Is the best good enough? The view from suppletion}

A friendly challenge to Hackl's analysis comes from morphology. Bobaljik (2012) studies suppletion in comparatives and superlatives cross-linguistically, and finds that only two of the imaginable four patterns are attested; see (11). This leads him to the Containment Hypothesis in (12)-(13).

(11) The Comparative-Superlative Generalizations (Bobaljik 2012)

$$
\begin{array}{ll}
\text { ABB } & \text { good }- \text { better }- \text { best } \\
\text { ABC } & \text { bonu }- \text { melior }- \text { optimus } \\
\text { AAB } * & \text { good }- \text { gooder }- \text { best } \\
\text { ABA } * & \text { good }- \text { better }- \text { goodest }
\end{array}
$$

(12) The Containment Hypothesis (Bobaljik 2012)

The representation of the superlative properly contains that of the comparative.

[[[ adjective ] comparative ] superlative ] 'Adj + more than + all others'

* [[ adjective ] superlative ] 'Adj + more than all others'

Bobaljik argues that Containment, teaming up with Distributed Morphology's Late Insertion (Realization), Under-specification, Elsewhere Ordering, and Locality, accounts for the Comparative-Superlative Generalizations, and for other generalizations he makes.

Why does Containment hold? According to Bobaljik, it is not part of UG per se. Instead, it is due to intrinsic limits on possible morpheme meanings, similarly to the assumption that each syntactic head can have no more than one interpretable feature (Sigurðsson 2004, Starke 2009, and others).

If Containment is correct then, Bobaljik observes, Hackl's many-est does not decompose enough. It accounts for the attested patterns $\mathrm{ABB}$ and $\mathrm{ABC}$, but does not explain why $\mathrm{ABA}$ and $\mathrm{AAB}$ are unattested. It ought to be what he notates as many-er-t. Some languages actually make that two-step composition overt in both regular and suppletive cases. Hungarian is one of them: the comparative suffix is $-b b$, and the superlative is formed by adding the prefix leg- to the comparative (sok 'many', több 'more', legtöbb 'most').

It is not difficult to recast Hackl's analyis in the manner Bobaljik's findings suggest (and Bobaljik doesn't say that it would be). Spelling out the revision is postponed to section 9, because the rest of the argument does not depend on it.

This paper will pursue the analysis [[[many] comparative] superlative], especially with reference to relative superlatives, with a brief note on absolute superla- 
tives. I hope to show that this analysis facilitates revisiting, resolving, and discovering some interesting issues:

Issue \#1 Mountains compared, or climbers compared?

Issue \#2 A definite article in indefinites?

Issue \#3 Absolute, non-partitive most is generic in English and Hungarian, but more and relative the most are not.

\section{A classical dilemma: what do relative superlatives compare?}

Heim interpreted sentences with relative superlatives such as climb the highest/most mountains as ones that compare climbers with respect to how high, or how many, mountains they climbed. But not everyone was ready to take that for granted. ${ }^{3}$

"We differ from Heim in that for us both readings of the superlative noun phrase in [Who climbed the highest mountain?] involve comparing mountains relative to height..."

(Farkas \& Kiss 2000: 441)

"Do we compare the heights of the mountains climbed, or the climbing achievements of the climbers? Do the sentences mean different things depending on whether we compare mountain heights or mountain climbers' achievements?"

(Sharvit \& Stateva 2002: 453)

An intriguing situation! Outstanding semanticists puzzle, not so much over what the exact truth conditions are, but, what these sentences are about. And apparently, they come to different conclusions.

Below I will consider the two intuitions in their recent reincarnations, Hackl 2009 and Krasikova 2011. Krasikova's analysis of relative superlatives belongs to the same family as Farkas \& Kiss's and Sharvit \& Stateva's, but while F\&K and S\&S compare mountains, Krasikova directly compares degree sets associated with mountains (heights or cardinalities), which I believe is an advantage. Besides, the machinery she uses is simpler and more standard.

One way to see how the two analyses make different comparisons is to look at their definitions of the context set C. For Heim and Hackl, C is the set of individ-

\footnotetext{
${ }^{3}$ This issue is distinct from the one pertaining to whether absolute and relative superlatives are mere contextual variants, although the literature often interleaves them. For example, Farkas and Kiss are with Heim regarding the scope account of relative superlatives, although they disagree with her regarding the nature of the comparison, as the quote shows, and also regarding how scope is to be handled.
} 
uals who climbed some number of mountains or other. For Krasikova, C is the set of degree-sets that characterize cardinalities of mountains climbed by someone or other. For Heim/Hackl, JOHN climbed the most mountains says that John has the property of being the individual in $\mathrm{C}$ who is associated with the highest cardinality of mountains climbed. For Krasikova, it says that the unique largest degree-set in $\mathrm{C}$ that characterizes cardinalities of mountains climbed is associated with John.

Heim/Hackl

"compare climbers"

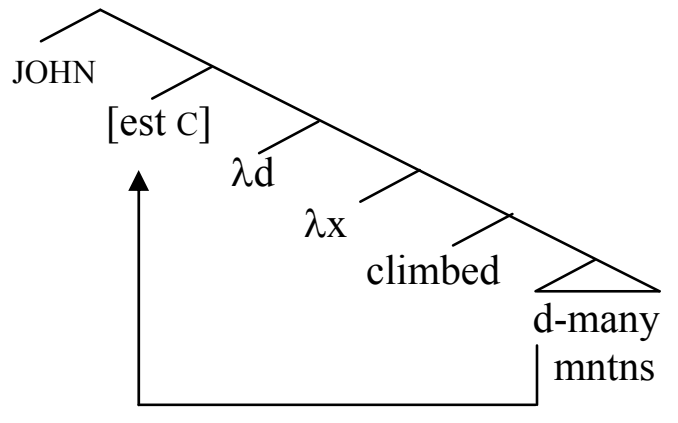

[-est C] $[\lambda d \lambda x . x$ climbed d-many mtns]

$[[$-est $]]=\lambda \mathrm{C} \lambda \mathrm{D} \lambda \mathrm{x} . \forall \mathrm{y} \in \mathrm{C}[\mathrm{x} \neq \mathrm{y} \rightarrow$ $\max \{\mathrm{d}: \mathrm{D}(\mathrm{d})(\mathrm{x})\}>\max \{\mathrm{d}: \mathrm{D}(\mathrm{d})(\mathrm{y})\}]$

$\mathrm{C}=\{\mathrm{x}: \exists \mathrm{d} . \mathrm{x}$ climbed d-many mtns $\}$

the is interpreted as $\exists$
Krasikova 2011

"compare mountain-set cardinalities"

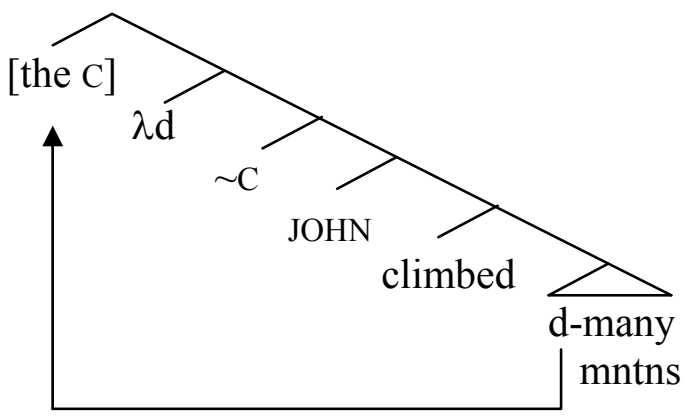

$[$ the $\mathrm{C}] *[\lambda \mathrm{d}$. JOHN climbed [d-many $\mathrm{mtns}] \sim \mathrm{C}]$ $[[$ the $]]=\lambda \mathrm{C} .1 \mathrm{D}\left[\mathrm{C}(\mathrm{D}) \rightarrow \forall \mathrm{D}^{\prime}\left[\mathrm{C}\left(\mathrm{D}^{\prime}\right)\right.\right.$ $\left.\rightarrow \mathrm{D}^{\prime} \subseteq \mathrm{D}\right]$

$$
\begin{array}{r}
\mathrm{C}=\{\mathrm{D}: \exists \mathrm{x}[\mathrm{D}=\lambda \mathrm{d} \exists \mathrm{Y}[\operatorname{mtns}(\mathrm{Y}) \wedge \\
\operatorname{climbed}(\mathrm{Y})(\mathrm{x}) \wedge|\mathrm{Y}| \geq \mathrm{d}]\}
\end{array}
$$

-est is an uninterpreted feature on most

I will argue that the Heim/Hackl analysis and the Krasikova analysis of relative superlatives are most likely truth-conditionally equivalent, but the differences are still signficant. They seem to be built off of two different comparative constructions, and inherit their properties. Heim/Hackl's is built off of a construction involving more, Krasikova's is built off of one involving the more.

The compositional details of the analyses will be discussed after the linguistic argument has been fleshed out, but it should be immediately obvious that following Bobaljik's advice and building superlatives out of comparatives is uniquely conducive to discovering such connections. 


\section{Meet the players: more and the more, most and the most}

I will be arguing that there exist two distinct comparative constructions on which correspondingly distinct superlative constructions are built. I want to stress right away that this paper is not a detailed study of comparatives. My goal here is to merely highlight the existence of the two constructions and convey an intuition regarding what they each mean. Achieving even this modest goal is made more difficult by the fact that there is a fair amount of English-internal cross-speaker variation, as well as a fair amount of cross-linguistic variation, concerning which of the four constructions are acceptable. So I have to ask the reader to bear with me and be open to the idea that some constructions that (s)he does not accept are acceptable to other speakers of English, or to speakers of other languages.

We start with more. Compare the following sets. By default, more receives nuclear stress, as in (15). It calls for a than-clause whose content is freely chosen. It can be than Bill (did), but it can also be than $\$ 100$. If the than-clause is absent, the ellipsis has the same range of meanings.

(15) a. Bill made $\$ 100$. John made MORE money than Bill (did) / than $\$ 100$.

b. Bill made \$100. John made MORE money.

The situation is different when more yields its default nuclear stress to another phrase, as in (16). No freely chosen than-clause is possible. The only natural choice is than the other, as a variant of of the two. If than Bill is added, we get a "third party comparison", as in (17a). The sequence in (17a) is incoherent, because JOHN made more money than Bill does not compare John and Bill, it compares John with other people, not mentioned, with respect to which of them made more money than Bill. If John and Bill receive parallel stresses, as in (17b), we get a simple narrative that will probably go on to tell us how the two guys dealt with the unequal situation. The second sentence in (17b) is not the kind of comparison those in (16) are.

(16) a. John and Bill worked. I am wondering WHO made more money.

b. John and Bill worked. Of the two, WHO made more money?

c. John and Bill worked. WHO made more money than the other?

d. John and Bill worked. Did JOHN make more money, or did BILL?

(17) a. John and Bill worked. \# JOHN made more money than Bill.

b. John and Bill worked. JOHN made more money than BILL.

Of interest to us is (16). Its more is reminiscent of relative superlatives. More than the other in (16c) is parallel to -est, viz. 'more than anyone else'. I submit that 
Heim \& Hackl's superlative semantics is built off of this comparative, with more than anyone else in the place of more than the other, corresponding to the fact that superlatives compare at least three things, whereas comparatives compare two, and thus "the other" is well-defined.

But alongside more we find the more. Many of my trusty American English informants do not like the latter, but ample naturally occurring examples can be found on the internet that come from carefully worded texts (e.g. the source of the first example is a biography printed in Britain in 1873). ${ }^{4}$

(18) Sarah wrote the more books, but Elizabeth is the better remembered.

Bunker Hill was not won by the side which had the more courage, but by that which had the more ammunition.

Who makes the more money, football players or baseball players?

Berlin will be fought out between General Jens and Sergeant Lewis and we all know who has the more medals between these two soldiers. In the event of a tie, the team that has the fewer points scored against it will win.

How do more and the more relate to each other? Does the difference consist in the presence or absence of the little word the? The answer is no. It is very clear that while more can take a than-clause, the more cannot.

JOHN made more money than the other. John made MORE money than Bill.

* JOHN made the more money than the other.

* John made the MORE money than Bill.

The conclusion is that these are two distinct constructions. Maybe some speakers of English have only one of them and some other speakers have both, but the difference is not whether a speaker uses an article in one and the same construction.

Structures corresponding to the more [of the two] are entirely normal in other languages, e.g. French and Hungarian. These replicate the inability of the more to take than.

(21) Qui a bu plus de vin, Jean ou Pierre?

Qui a bu le plus de vin, Jean ou Pierre?

\footnotetext{
${ }^{4}$ Caveat: Set aside conditional comparatives, such as The more we work, the less we earn. One reason to set them aside is that in some other languages they take the shape of vanilla correlatives, i.e. the fact that in English they have this particular shape may be more or less accidental.
} 
(22) Qui a bu plus de vin que Marie?

* Qui a bu le plus de vin que Marie?

$\begin{array}{lllllll}\text { Ki } & \text { ivott } & \text { több bort, } & \text { Jani vagy } & \text { Pali? } \\ \text { who } & \text { drank } & \text { more wine.acc } & \text { John or } & \text { Paul } \\ \text { Ki } & \text { itta } & \text { a több bort, } & \text { Jani } & \text { vagy } & \text { Pali? } \\ \text { who } & \text { drank } & \text { the more wine.acc } & \text { John } & \text { or } & \text { Paul }\end{array}$

$\begin{array}{llllll}\text { Ki } & \text { ivott } & \text { több } & \text { bort, } & \text { mint } & \text { Mari? } \\ \text { who } & \text { drank } & \text { more } & \text { wine.acc than } & \text { Mary } \\ \text { * Ki } & \text { itta } & \text { a } & \text { több bort, } & \text { mint Mari? } \\ \text { who } & \text { drank } & \text { the } & \text { more wine.acc } & \text { than Mary }\end{array}$

The possible formal identity of superlatives is not a confound. In French, le plus de also serves as the superlative, but in Hungarian, the superlative is a legtöbb.

If we have two constructions, how do the meanings differ? Hungarian speakers and English speakers who accept both more and the more report a distinction in terms of what issue the two constructions raise:

(25) Who drank more wine? / Ki ivott több bort? 'interested in what people did'

(26) Who drank the more wine? / Ki itta a több bort? 'interested in the greater amount of wine drunk, and who it was drunk by'

This distinction is exactly the same as the distinction between Heim and Hackl's and Krasikova's views of superlatives.

Does most also exist in the relative superlative sense, alongside the most? It is clearly dispreferred, but again, fairly convincing examples occur on the internet. (I searched for most+mass noun, because that eliminates the proportional most confound; see section 11.)

(27) When only one promotional code can be used - pick the one that saves you most money!

[I]t's good to keep track of all your expenses in a spreadsheet, so you can see what you are spending most money on in the garden.

Which animal has most hair per square inches on its body?

Most races are won by the guy who has most luck at the collisions at the start. 
Compositionality without word boundaries

Likewise, I initially thought that bare legtöbb 'most' and legkevesebb 'least' are not possible in my Hungarian, but I find many of the naturally occurring examples acceptable. Also, most is perfectly acceptable in English as an adverbial superlative: Who spoke most? At present I have no idea why that contrast exists.

\section{Why two views about relative superlatives?}

We are now ready to come back to the question why there are two competing views in the literature about relative superlatives. As has been anticipated in the foregoing section, my hypothesis is that the two views are built off of different comparatives. The $\%$ sign indicates that acceptability varies across speakers.

\begin{tabular}{|l|l|l|}
\hline & $\begin{array}{l}\text { compares } \\
\text { climbers }\end{array}$ & $\begin{array}{l}\text { compares } \\
\text { (cardinalities of) mountains }\end{array}$ \\
\hline $\begin{array}{l}\text { two things } \\
\text { compared }\end{array}$ & $\begin{array}{l}\text { more mountains } \\
\text { (than...) }\end{array}$ & $\begin{array}{l}\% \text { the more mountains } \\
\text { (*than...) }\end{array}$ \\
\hline $\begin{array}{l}\text { more than two things } \\
\text { compared }\end{array}$ & $\begin{array}{l}\text { most mountains } \\
\text { tho most mountains } \\
\text { (Heim, Hackl) }\end{array}$ & $\begin{array}{l}\text { 'the largest D associated with any' } \\
\text { (Krasikova) }\end{array}$ \\
\hline
\end{tabular}

Who is "right"? If the two analyses are indeed truth-conditionally equivalent, the question may seem spurious. But if composition matters, then the question can still be interesting. Probably, each way of building superlatives is "right" for some languages, and both may coexist in (varieties of) the same language.

The Heim/Hackl analysis seems especially well-suited for the Russian relative amount superlative bol'she vsex/vsego 'most', literally, 'more than all'. Of particular interest is the fact that the choice of singular vs. plural genitive for 'all' is sensitive to the kind of things compared, as envisioned on that analysis. (I thank Sonya Kasyanenko for the Russian data. See also Stateva 2004.)

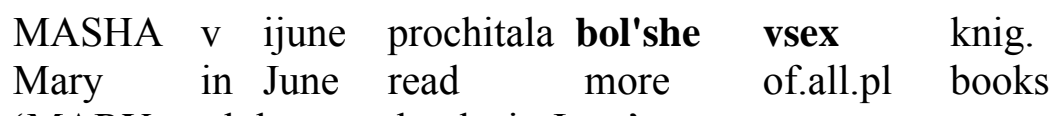

'MARY read the most books in June'

(=Mary read more books in June than anyone else did)

(29) Bol'she vsego knig Masha prochitala $v$ ijune. more of.all.sg books Mary read in June 'Mary read the most books in JUNE' (=Mary read more books in June than in any other month) 
Anna Szabolcsi

With respect to English and Hungarian, Krasikova's analysis has the advantage that it affords a clear account of the role of the definite article, an issue that Heim/Hackl have nothing to say about. I review Krasikova's account in the next section. But I have no ready explanation of the semi-gaps (\% judgments) pertaining to most and the more in English, and of why English favors "nonmatching" amount comparatives and amount superlatives, speaking in terms of the table above.

Finally, the two views seem to correspond to different intuitions by speakers and by scholars (witness the old debate) and, possibly, to different processing strategies. Assuming Interface Transparency (Hackl 2009; Lidz et al. 2011), this might be experimentally testable.

(30) Interface Transparency Thesis (ITT), Lidz et al. 2011

The verification procedures employed in understanding a declarative sentence are biased towards algorithms that directly compute the relations and operations expressed by the semantic representation of that sentence.

\section{What is the definite article doing in an indefinite?}

Let us inspect the two analyses, again, in view of the preliminary findings.

Heim/Hackl: compare climbers

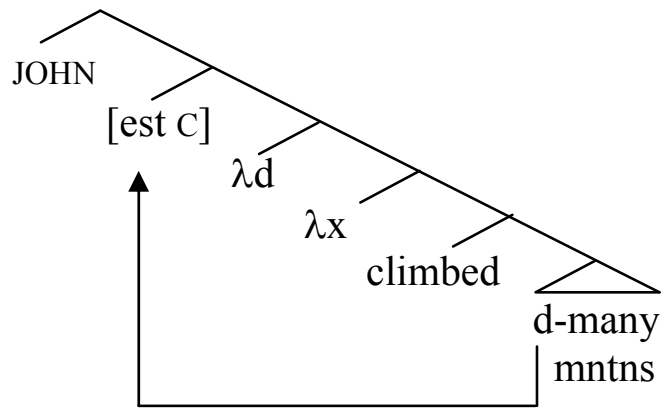

[-est C] $[\lambda d \lambda x . x$ climbed d-many mtns]

$$
\begin{aligned}
& {[[\text {-est }]]=\lambda \mathrm{C} \lambda \mathrm{D} \lambda \mathrm{x} . \forall \mathrm{y} \in \mathrm{C}[\mathrm{x} \neq \mathrm{y} \rightarrow} \\
& \quad \max \{\mathrm{d}: \mathrm{D}(\mathrm{d})(\mathrm{x})\}>\max \{\mathrm{d}: \mathrm{D}(\mathrm{d})(\mathrm{y})\}]
\end{aligned}
$$

$\mathrm{C}=\{\mathrm{x}: \exists \mathrm{d} . \mathrm{x}$ climbed d-many mtns $\}$

the is interpreted as $\exists$
Krasikova 2011: compare degree-sets

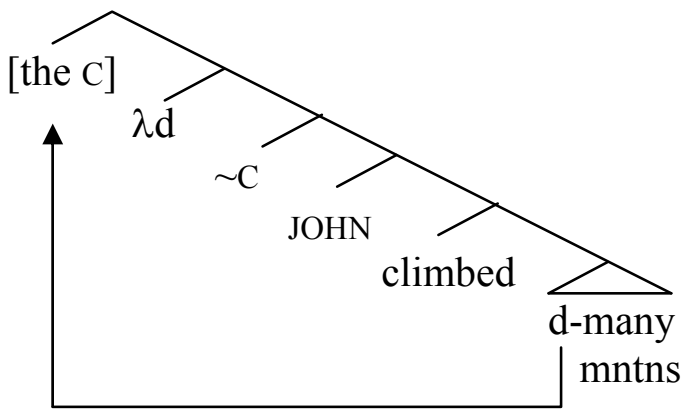

$[$ the $\mathrm{C}] *[\lambda \mathrm{d}$. JOHN climbed [d-many $\mathrm{mtns}] \sim \mathrm{C}]$

$$
\begin{aligned}
& {[[\text { the }]]=\lambda \mathrm{C} .1 \mathrm{D}\left[\mathrm { C } ( \mathrm { D } ) \rightarrow \forall \mathrm { D } ^ { \prime } \left[\mathrm{C}\left(\mathrm{D}^{\prime}\right)\right.\right.} \\
& \left.\rightarrow \mathrm{D}^{\prime} \subseteq \mathrm{D}\right] \\
& \mathrm{C}=\{\mathrm{D}: \exists \mathrm{x}[\mathrm{D}=\lambda \mathrm{d} \exists \mathrm{Y}[\operatorname{mtns}(\mathrm{Y}) \wedge \\
& \operatorname{climbed}(\mathrm{Y})(\mathrm{x}) \wedge|\mathrm{Y}| \geq \mathrm{d}]\}
\end{aligned}
$$

-est is an uninterpreted feature on most 
Compositionality without word boundaries

We see that both Heim/Hackl and Krasikova put all the eggs in one basket but in different baskets. Heim/Hackl write all the semantics into -est, and convert the into $\exists$. Krasikova writes all the semantics into the and its restrictor, and -est spells out an uninterpreted syntactic feature for her. Clearly, both analyses need to be broken down more. In order to do that, we need to know more about the definite article.

The fact that relative superlatives, in contrast to absolute superlatives, are indefinite was one of the central concerns in Szabolcsi 1986. Szabolcsi observed that whatever phenomenon the literature claims distinguishes between "definite" and "indefinite" noun phrases, relative superlatives persistently pattern with "indefinites" with respect to that phenomenon. Extraction out of DP, existential there-contexts, relational have-contexts, and discontinuous amount expressions were among the cases considered. For example, ${ }^{5}$

(31) \# Who has the descendants? (relation, not capture)

\# Does ARTHUR have the descendants? (relation, not capture)

(32) Who has the most/fewest descendants? (relation, not capture) Does ARTHUR have the most/fewest descendants? (relation, not capture)

Doktorral ITT találkoztam hárommal / * a hárommal.
doktor.with here met.I
'Of doctors it's here that I met with three / * with the three'

$\begin{array}{llll}\text { Doktorral } & \text { ITT találkoztam a legtöbbel / a legkevesebbel. } \\ \text { doctor.with } & \text { here met.I } & \text { the most.with the fewest.with }\end{array}$
'Of doctors it's here that I met with the most/the fewest'

Szabolcsi 2010:172 made the new observation that relative superlatives, in contrast to absolute superlatives, host adnominal each:

\footnotetext{
${ }^{5}$ The observation that relational have requires an indefinite object is due to B. Partee. The discontinuous amount expressions are reminiscent of German, Japanese, etc. As (33)-(34) show, in Hungarian all the discontinuous parts exhibit the same case marker, so it is clear that the amount phrases are not simple frequency adverbs, whatever their proper analysis might be. Neither Szabolcsi 1986, nor the present paper offers a theory of why all these contexts require indefinites. The issue is why relative superlatives consistently pattern with indefinites in these contexts.
} 
Anna Szabolcsi

(35) \# Who showed the children most of the books each?

ought to mean 'Who showed each child a possibly different absolute majority of the books?'

(36) Who gave the children the most/the fewest books each?

'Who gave more/fewer books per child than how many books anyone else did?'

This is especially interesting, because adnominal each does not only require its host to be an indefinite, it requires its host to be a "counting quantifier" - i.e. a degree quantifier. Szabolcsi 2010 concludes that relative superlatives are such quantifiers.

Notice now that (on my view) the Heim/Hackl analysis is not an analysis of relative superlative the most; it is in fact an analysis of the marginally acceptable relative superlative most (or, of the relative superlative bol'she vsex/vsego). If so, it should not be faulted for not offering an insight into what the definite article is doing in an indefinite. There really is no definite article in the construction they analyze (although they assume that there is one, and convert it into $\exists$ ). ${ }^{6}$

In contrast, the definite article takes center stage in Krasikova's analysis. Krasikova (2011) offers a natural account of the definite article in relative superlatives that is consistent with the findings of Szabolcsi 1986, 2010. According to Krasikova, the unicity expressed by the definite article pertains to degree sets, not to individuals:

(37) Who has the tallest descendant / the most descendants?

'for which $x$, the maximal degree set s.th. someone has descendant(s) with tallness/cardinality of that degree is a degree-set s.th. $x$ has descendant(s) with tallness/cardinality of that degree?'

The fact that Krasikova compares degree sets associated with individuals and not individuals themselves gives her analysis a slight truth-conditional edge over Farkas \& Kiss 2000. In their fn.15 F\&K claim that since the highest mountain refers to a singleton set of mountains climbed, a plural must be used to avoid presupposition failure in a situation like the following:

\footnotetext{
${ }^{6}$ Szabolcsi 1986 did not develop a compositional semantics. However, some hints can be read off of the syntax. The paper treated [the -est] as a single unit. [the -est] was generated either in the position of the definite article and universals under $\mathrm{N}^{\prime \prime \prime}$ (in absolute superlatives) or in the position of numerals under $\mathrm{N}^{\prime \prime}$ (in relative ones). The latter moved at LF to take sentential scope. With the benefit of hindsight, the $\mathrm{N}^{\prime \prime}$-internal [the -est] is naturally understood as a degree quantifier.
} 
Compositionality without word boundaries

(38) John climbed a $3000 \mathrm{ft}$. mountain and a $2500 \mathrm{ft}$. mountain. Everybody else climbed mountains below $2000 \mathrm{ft}$.

JOHN climbed the highest mountain - predicted by F\&K to fail to refer

JOHN climbed the highest mountains - predicted by F\&K to be perfect

I believe the prediction concerning the singular example is not right: both sentences are true and felicitous. Krasikova's account makes the correct prediction (and so does Heim and Hackl's).

On the other hand, C. Barker (p.c.) points out that in case the two mountains John climbed are of equal height, say, both $3000 \mathrm{ft}$., then JOHN climbed the highest mountain is indeed a presupposition failure. As far as I can see, Krasikova's semantics does not directly predict that: there is a unique degree set, albeit it is associated with two mountains. ${ }^{7}$ But perhaps this can be remedied, i.e. the desired presupposition failure can be generated, along the lines of Champollion \& Sauerland's (2010) assessment of Haddock's puzzle. ${ }^{8}$

\section{Assembling the two relative superlatives, \% most and the most}

We are now ready to replicate Heim and Hackl's and Krasikova's semantics following Bobaljik's recipe: [[[d-many/much] comparative] superlative]. Recall that on my view, both are valid, and necessary for slightly different constructions. I sketch derivations for both, just to show that they can be assembled using the same interpretations for those bits and pieces that they share. This serves to demonstrate that these constructions can in principle co-exist in the same language (as they in fact do, although they are not equally preferred), and that the fact that different languages favor different constructions does not entail a crosslinguistic discrepancy in the meanings of the smallest pieces.

I do not provide a general solution, just show how simple examples can be derived in a manner that everybody can adjust to their favorite framework, involving either LF-movement or in-situ scoping in a type-logical grammar. The treatment of the sentence-internal reading of the adjective same in Barker 2007 and Solomon 2009 are good models for the latter.

\footnotetext{
${ }^{7}$ Heim/Hackl predict no presupposition failure, either, but if their claims should be understood to hold for some construction that contains no definite article at all, then that is alright.

${ }^{8}$ The puzzle concerns the fact that The circle in the square is white is not a presupposition failure when there are multiple circles and squares, although only one circle-in-a-square. It is the analogue of the latter requirement that the two mountains with equal heights would fail. I will not attempt to implement this here.
} 
I borrow d-much/many from Cresti's (1995) split-scope analysis of how manyquestions. ${ }^{9}$ I will retain the cardinality notation $|\cdot|$ even for masses, because it is more transparent than $\mu$. -Er comes from Heim 1985, and the generalized quantifier interpretation of than Bill (did) from Larson 1988 and Heim 2006.

$$
\begin{array}{ll}
\text { d-many/much } & \lambda \mathrm{N} \lambda \mathrm{d} \exists \mathrm{a}[\mathrm{N}(\mathrm{a}) \wedge|\mathrm{a}| \geq \mathrm{d}] \\
\text {-er } & \lambda \mathrm{G} \lambda \mathrm{F}[\max (\mathrm{F})>\max (\mathrm{G})] \\
\text { than Bill (did) } & \lambda \mathrm{P}\left[\mathrm{P}\left(\operatorname{Bill}{ }^{\prime}\right)\right]
\end{array}
$$

On the Heim/Hackl approach, the VP of sentence (15), John made MORE money than Bill (did) can be looked upon as (42), where each of the superscripts correspond to the application of a combinator, as in (43), to the elements defined above. This VP denotes the set of individuals who made a greater amount of money than the amount of money Bill made.

$$
\begin{aligned}
& \text { made MORE money than Bill (did) = } \\
& \text { than_Bill_did } \left.{ }^{\delta}\left(-\operatorname{er}^{\gamma}\left(\left(d-\text { much }^{\alpha}(\text { money })\right)^{\beta} \text { (made }\right)\right)\right) \\
& \lambda \mathrm{y}\left[\max \left(\lambda \mathrm{d} \exists \mathrm{a}\left[\operatorname{made}^{\prime}(\mathrm{a})(\mathrm{y}) \wedge \operatorname{money}^{\prime}(\mathrm{a}) \wedge|\mathrm{a}| \geq \mathrm{d}\right]\right)\right. \\
& \left.>\max \left(\lambda \mathrm{d} \exists \mathrm{a}\left[\operatorname{made}^{\prime}(\mathrm{a})\left(\operatorname{Bill}^{\prime}\right) \wedge \operatorname{money}^{\prime}(\mathrm{a}) \wedge|\mathrm{a}| \geq \mathrm{d}\right]\right)\right]
\end{aligned}
$$

$$
\begin{aligned}
& \alpha=\lambda \mathrm{g} \lambda \mathrm{h} \lambda \mathrm{f}[\mathrm{g}(\mathrm{fh})] \\
& \beta=\lambda \mathrm{X} \lambda \mathrm{R} \lambda \mathrm{z}[\mathrm{X}(\lambda \mathrm{g} \lambda \mathrm{y}[\mathrm{R}(\mathrm{y})(\mathrm{z}) \wedge \mathrm{g}(\mathrm{y})])] \\
& \gamma=\lambda \mathrm{Y} \lambda \mathrm{P} \lambda \mathrm{x} \lambda \mathrm{y}[\mathrm{Y}(\mathrm{Px})(\mathrm{Py})] \\
& \delta=\lambda \mathrm{Z} \lambda \mathrm{T} \lambda \mathrm{u}[\mathrm{Z}(\mathrm{Tu})]
\end{aligned}
$$

The word more ${ }_{H H}$ implicated here has the following interpretation. $N$ is a variable of type $<\mathrm{e}, \mathrm{t}>$ (nouns), and $R$ of type $<\mathrm{e},<\mathrm{e}, \mathrm{t}>>$ (transitive verbs).

$$
\begin{array}{r}
\quad \text { more }_{H H} \quad \lambda \mathrm{N} \lambda \mathrm{R} \lambda \mathrm{x} \lambda \mathrm{y}[\max (\lambda \mathrm{d} \exists \mathrm{a}[\mathrm{R}(\mathrm{a})(\mathrm{y}) \wedge \mathrm{N}(\mathrm{a}) \wedge|\mathrm{a}| \geq \mathrm{d}]) \\
>\max (\lambda \mathrm{d} \exists \mathrm{a}[\mathrm{R}(\mathrm{a})(\mathrm{x}) \wedge \mathrm{N}(\mathrm{a}) \wedge|\mathrm{a}| \geq \mathrm{d}])]
\end{array}
$$

In (16), WHO made more money than the other? contains (45), and the version WHO made more money? contains a phonetically null version thereof.

\footnotetext{
${ }^{9}$ Cresti decomposes how many people into wh-how and t-many people; the latter contains an existential quantifier for pluralities with cardinality $t$.

(i) How many people should John talk to?

'for what number $n$, John should talk to $n$ people'

$\lambda \mathrm{p} \exists \mathrm{n}\left[\operatorname{number}(\mathrm{n}) \wedge \mathrm{p}={ }^{\wedge} \operatorname{should}\left({ }^{\wedge} \exists^{\mathrm{n}} \mathrm{x}\left[\operatorname{person}^{\prime}(\mathrm{x}) \wedge \operatorname{talk}^{\prime}\left(\operatorname{John}^{\prime}, \mathrm{x}\right)\right]\right)\right]$
} 
Compositionality without word boundaries

than the other

$\lambda \mathrm{T} \lambda \mathrm{u}[\mathrm{T}(\mathrm{vv}[\mathrm{v} \neq \mathrm{u} \wedge \mathrm{v} \in \mathrm{C}\{\mathrm{v}, \mathrm{u}\})])(\mathrm{u})]$

where $\mathrm{C}\{\mathrm{v}, \mathrm{u}\}$ is retrieved from the context

The naturally occurring examples in (27) as well as the Russian (28)-(29) demand the Heim/Hackl analysis of the superlative. The morpheme that Bobaljik notates as - $t$ is a universally quantified than-clause, cf. than anyone else. In this spirit, the VP of WHO made \%most money? is assembled using (46).

$$
\begin{aligned}
& \text { - } t=\text { than_anyone_else } \begin{array}{l}
\lambda \mathrm{T} \lambda \mathrm{u} \forall \mathrm{v}[\mathrm{v} \neq \mathrm{u} \wedge \mathrm{v} \in \mathrm{C}][\mathrm{T}(\mathrm{v})(\mathrm{u})] \\
\text { where }|\mathrm{C}|>2 \text { and } \mathrm{C} \text { is retrieved from the context }
\end{array} \\
& \text { made \%most money }= \\
& -t\left(- \text { er }^{\gamma}\left(\left(d-\text { much }^{\alpha}(\text { money) })\right)^{\beta}(\operatorname{made})\right)\right) \\
& \lambda \mathrm{u} \forall \mathrm{v}[\mathrm{v} \neq \mathrm{u} \wedge \mathrm{v} \in \mathrm{C}]\left[\max \left(\lambda \mathrm{d} \exists \mathrm{a}\left[\operatorname{made}^{\prime}(\mathrm{a})(\mathrm{u}) \wedge \operatorname{money}^{\prime}(\mathrm{a}) \wedge|\mathrm{a}| \geq \mathrm{d}\right]\right)\right. \\
& \left.>\max \left(\lambda \mathrm{d} \exists \mathrm{a}\left[\operatorname{made}^{\prime}(\mathrm{a})(\mathrm{v}) \wedge \operatorname{money}^{\prime}(\mathrm{a}) \wedge|\mathrm{a}| \geq \mathrm{d}\right]\right)\right]
\end{aligned}
$$

We do not have to deal with the definite article: this construction has none.

We derive JOHN made the more money and JOHN made the most money using Krasikova's strategy. It seems useful to start by showing how Krasikova's own formalization of the most can be built from the kind of pieces we want. To recap, Krasikova (2011) uses the components in (48)-(50). She assumes that -est spells out an uninterpretable syntactic feature, so -est does not show up in her semantics at all. Our task is to redistribute the bits of Krasikova's semantics so that the, -er, and -t can each be meaningful. We will not need a than-clause: recall that the presence of an actual overt the is not compatible with a than-clause.

$$
\begin{aligned}
& {[\text { the } \mathrm{C}] *[\lambda \mathrm{d} \text {. JOHN made }[\mathrm{A} d \text { most money }] \sim \mathrm{C}]} \\
& {[[\text { the }]]=\lambda \mathrm{C} .1 \mathrm{D}\left[\mathrm{C}(\mathrm{D}) \rightarrow \forall \mathrm{D}^{\prime}\left[\mathrm{C}\left(\mathrm{D}^{\prime}\right) \rightarrow \mathrm{D}^{\prime} \subseteq \mathrm{D}\right]\right.} \\
& \mathrm{C}=\{\mathrm{D}: \exists \mathrm{x}[\mathrm{D}=\lambda \mathrm{d} \exists \mathrm{Y}[\operatorname{money}(\mathrm{Y}) \wedge \operatorname{made}(\mathrm{Y})(\mathrm{x}) \wedge|\mathrm{Y}| \geq \mathrm{d}]\}
\end{aligned}
$$

The revision uses the same $d$-much (39) and -er (40) as the Heim/Hackl derivations. Krasikova's C is definable in terms of a segment of (42). D is the same variable over degree-sets as in Krasikova 2011.

\footnotetext{
10 "Beck [2011] assumes that a set of degrees may saturate the degree argument of some degree predicate by acting as a plurality of degrees interpreted distributively. To derive distributive readings, she introduces Link's star operator, to the effect that the plurality of degrees receives sentential scope... Given the standard definition of *, which in this case turns a degree set into its power set, the resulting truth conditions boil down to [i] (words replaced by AS):
}

[i] $\exists \mathrm{X}\left[\mathrm{X}\right.$ is money in $w \wedge$ John made $\mathrm{X}$ in $w \wedge \forall \mathrm{d}\left[\mathrm{d} \in[[\right.$ the $\left.\left.\mathrm{C}]](w) \rightarrow \operatorname{card}_{w}(\mathrm{X}) \geq \mathrm{d}\right]\right]$ "

(Krasikova 2011:411) 
d-much

-er

$\left(d-\text { much }^{\alpha}(\text { money })\right)^{\beta}$ (made)

$\mathrm{C}$ $\lambda \mathrm{N} \lambda \mathrm{d} \exists \mathrm{a}[\mathrm{N}(\mathrm{a}) \wedge|\mathrm{a}| \geq \mathrm{d}]$

$\lambda \mathrm{G} \lambda \mathrm{F}[\max (\mathrm{F})>\max (\mathrm{G})]$

$\lambda \mathrm{z} \lambda \mathrm{d} \exists \mathrm{a}[\operatorname{made}(\mathrm{a})(\mathrm{z}) \&$ money $(\mathrm{a}) \&|\mathrm{a}| \geq \mathrm{d}]$

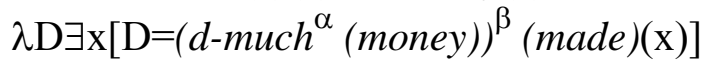

Now replace [[the C]] with (55). Let it suffice to give the gist of my proposal. The content that Krasikova packs into the can be redistributed to three operators. The iota-operator over degree-sets can be looked upon as a definite article that I dub THE, the universal over degree-sets can be looked upon as a superlative morpheme that I dub of-all; and $D^{\prime} \subseteq D$ can be recast as $D=D^{\prime} \vee-\operatorname{er}(D)(D)$, which crucially uses our comparative $-e^{11}$

$$
[[\text { THE of-all }-\operatorname{er~} C]] \quad \mathrm{iD}\left[\mathrm{C}(\mathrm{D}) \rightarrow \forall \mathrm{D}^{\prime}\left[\mathrm{C}\left(\mathrm{D}^{\prime}\right) \rightarrow\left(\mathrm{D}=\mathrm{D}^{\prime} \vee-\operatorname{er}\left(\mathrm{D}^{\prime}\right)(\mathrm{D})\right)\right]\right]
$$

Finally, following Krasikova, finish the computation with (56). Based on the convention explained in fn. 10, this yields (57), viz. there is an amount of money that John made and is the largest among the amounts that anyone made. (I skip Krasikova's well-taken world variables to make the formula more similar to what I had in the rest of the paper.)

$$
\begin{aligned}
& {[[\text { THE of-all -er } C]] *\left[\left(d \text {-much }{ }^{\alpha}(\text { money })\right)^{\beta}(\text { made })(\text { John })\right]} \\
& \exists \mathrm{X}[\mathrm{X} \text { is money } \wedge \mathrm{John} \text { made } \mathrm{X} \wedge \forall \mathrm{d}[\mathrm{d} \in[[\text { THE of-all } \text {-er } C]] \rightarrow|\mathrm{X}| \geq \mathrm{d}]]
\end{aligned}
$$

In the spirit of the preceding discussion, JOHN made the more money should have of-the-two in the place of of-all in (55).

To summarize, this section did not introduce semantic innovations. The goal was to replicate Heim and Hackl's semantics and Krasikova's semantics, in a way that allows them to peacefully co-exist, rather than compete. My claim is that all these constructions are exemplified across languages, although they are not equally preferred choices in the same language. So far as I can see, they are truthconditionally equivalent, but they raise the issue of comparison in different terms.

This concludes the main argument of the paper. Section 10 below takes up the role of focus in comparatives and relative superlatives. Section 11 observes that the absolute readings of non-partitive most in English and its counterpart $a$ legtöbb in Hungarian are generics of sorts, unlike die meisten in German. This

\footnotetext{
${ }^{11}$ Krasikova 2012, which I have not seen yet, pursues a similar revision of Krasikova 2011.
} 
Compositionality without word boundaries

fact makes it a more or less open question whether these proportional quantifiers fit into the picture as seamlessly as was assumed in Hackl 2009.

\section{Degree quantifiers and focus}

Although no general proposal has been made above for how relative superlatives are licensed, the reader may wonder why focus has not been invoked. The reason is that focus per se is not a critical element. Already Szabolcsi 1986 argued that it was not a critical element, and Heim 1999 cited further examples that seem to confirm that position. To recap, Szabolcsi 1986 showed that relative superlatives are possible in Hungarian sentences that contain a contrastive focus, or a question-word, or a relative pronoun, and they are not possible in minimally different examples that lack these. The paper argued that focus per se cannot be the relevant factor, since relative pronouns are not foci. They do not bear nuclear stress, they do not occur in the preverbal position in Hungarian, and theories of focus such as Rooth 1985 do not assume that they introduce alternatives. The same holds for relative pronouns and superlatives in English (Szabolcsi 1986: (22)):

We should console the girl who got the fewest letters.

In fact, in English none of these factors are really necessary, as was pointed out in Heim 1999, among others. For example:

(59) John climbed the highest mountain.

OK 'higher than anyone else'

(60) How do you win this competition? By PRO making the fewest mistakes.

(61) I don't want to PRO get the fewest letters.

The account in Szabolcsi 1986 did not specifically need focus, although it had a good use for it when focus was present. Note that WH in (62) covers both interrogative and relative $\mathrm{WH}-$ phrases.

(62) "WH/FOCUS license the comparative ${ }^{12}$ reading of the superlative because they give rise to a proposition containing a variable, and the "frame of comparison" can be defined in terms of this open formula." (Szabolcsi 1986: (24))

Apparently the "frame of comparison" can be defined in even more ways.

\footnotetext{
${ }^{12}$ Szabolcsi's term for what have come to be called relative superlatives was comparative superlatives.
} 
An interesting connection between comparatives, relative superlatives, and focus was discovered by Sharvit \& Stateva:

(63) "We suggest that the default focus (at least in English) for a sentence containing a superlative expression is the superlative morpheme itself. When -est itself is focused, it does not function as a focus-sensitive operator, but it still invokes contextually relevant alternatives."

(Sharvit \& Stateva 2002: 485)

This should recall the discussion in section 6. It seems that both comparatives and relative superlatives are by default foci in English as well as Hungarian. They only lose their default focus when it is overridden by a question-word or contrastive focus; they do not lose it to a relative pronoun or PRO.

The significance of the observation, I believe, is that the above behavior (focus by default, yielding to question-words or contrastive foci) is the classical behavior of all counting quantifiers in Hungarian, a language in which nuclear stress goes hand in hand with constituent order, and thus the patterns are more visible to the naked eye (Szabolcsi 1997, 2010: §10.5). Distributional and semantic considerations above have lead us to regard comparatives and relative superlatives as counting quantifiers, i.e. as degree quantifiers, so the nuclear stress facts follow from this characterization.

It is no longer a mystery, then, why relative superlatives exhibit the particular interaction with focus that they do. They do not require the presence of focus on another phrase; in its absence they bear focus themselves. This should clear the way for future work directed at a better understanding of exactly how "frames of comparison" are determined.

\section{A puzzle concerning absolute superlative most (of the)}

Recall that Hackl's (2009) argument for the decomposition of most into d-many and -est rests on the insight that proportional most is nothing else than absolute superlative most. More precisely, Hackl presents the argument with reference to German. In German, the phrase die meisten Berge is ambiguous between 'most (of the) mountains' and 'the most mountains'.

At first sight, absolute superlatives fit seamlessly into the system developed above. They can be obtained as a special case of the Heim/Hackl semantics for relative superlatives: the case in which the identity relation " $=$ " is fed to the relative superlative, instead of a relation denoted by a transitive verb. One effect of using "=" is that it confines the scope of the superlative to the DP; the other is that it performs Existential Disclosure (Dekker 1993) on d-many mountains, wiping out its $\exists$ (i.e. the "lower" existential in Cresti 1995). The result is the set of moun- 
Compositionality without word boundaries

tain-pluralities whose cardinality is greater than that of any competing mountainplurality. This will be existentially closed in the end.

The interpretation assigned to \%most in (47) is used in (64). Applying it to mountains and "=" we obtain absolute superlative most mountains in its preexistential-closure shape, replicating the interpretation in Hackl 2009.

$$
\begin{aligned}
& \text { most mountains }=\% \operatorname{most}(\text { mountains })(=) \\
& =\lambda \mathrm{N} \lambda \mathrm{R} \lambda \mathrm{u} \forall \mathrm{v}[\mathrm{v} \neq \mathrm{u}][\max (\lambda \mathrm{d} \exists \mathrm{a}[\mathrm{R}(\mathrm{a})(\mathrm{u}) \wedge \mathrm{N}(\mathrm{a}) \wedge|\mathrm{a}| \geq \mathrm{d}]) \\
& \quad>\max (\lambda \mathrm{d} \exists \mathrm{a}[\mathrm{R}(\mathrm{a})(\mathrm{v}) \wedge \mathrm{N}(\mathrm{a}) \wedge|\mathrm{a}| \geq \mathrm{d}])]\left(\operatorname{mntns}^{\prime}\right)(=) \\
& =\lambda \mathrm{u} \forall \mathrm{v}[\mathrm{v} \neq \mathrm{u}][\max (\lambda \mathrm{d} \exists \mathrm{a}[\mathrm{a}=\mathrm{u} \wedge \operatorname{mntns}(\mathrm{a}) \wedge|\mathrm{a}| \geq \mathrm{d}]) \\
& \left.\quad>\max \left(\lambda \mathrm{d} \exists \mathrm{a}\left[\mathrm{a}=\mathrm{v} \wedge \operatorname{mntns}^{\prime}(\mathrm{a}) \wedge|\mathrm{a}| \geq \mathrm{d}\right]\right)\right] \\
& =\lambda \mathrm{u} \forall \mathrm{v}[\mathrm{v} \neq \mathrm{u}]\left[\max (\lambda \mathrm{d}[\operatorname{mntns}(\mathrm{u}) \wedge|\mathrm{u}| \geq \mathrm{d}])>\max \left(\lambda \mathrm{d}\left[\operatorname{mntns}^{\prime}(\mathrm{v}) \wedge|\mathrm{v}| \geq \mathrm{d}\right]\right)\right]
\end{aligned}
$$

It turns out, however, that the German results do not directly carry over to English, or to Hungarian, for that matter. Consider the following.

(65) Absolute (proportional) superlative most vs. most of the:

Mary hates most sandwiches.

Mary tasted most sandwiches.

Mary tasted most of the sandwiches.

\# Mary drank most whiskey.

Mary drank most of the whiskey. $\checkmark$ kinds $\quad \#$ pieces

$\checkmark$ kinds $\quad$ \# pieces

$\checkmark$ kinds $\quad \checkmark$ pieces

\# stuff

$\checkmark$ stuff

(66) Comparative more and relative superlative the most:

MARY tasted more/the most sandwiches.

MARY drank more/the most whiskey.

$\checkmark$ pieces
$\checkmark$ stuff

What we see is that bare proportional most is a generic of sorts and, most strikingly, it does not combine with mass nouns. Mary drank most whiskey cannot mean that Mary drank more than half of a bottle of whiskey (it is in fact not an acceptable sentence). In contrast, comparative more and relative superlative the most are non-generics, and they happily combine with mass nouns (as the make (the) more/the most money examples above have amply demonstrated). Proportional bare most contrasts with partitive most of the, which can, but need not, be generic and works with mass nouns.

The most vs. most of the facts above are tightly related to those pertaining to collective, cumulative, and distributive readings discussed by Crnic (2009). With 
reference to Matthewson 2001, Nakanishi \& Romero 2004, and Lønning 1987, Crnic argues that bare most (on its standard, absolute reading) modifies bare plurals and is thus a kind-quantifier. Kind-quantifiers, in turn, are always distributive. Subtrigging enables the creation of one-member kinds and thus most NP can occur in episodic sentences, but still, only with a distributive reading.

Crnic offers an account of why the combination of most with a non-kind predicate can only result in a generic interpretation, using the DKP (Derived Kind Predication) and $\mathrm{GEN}_{\mathrm{C}}$ operators of Chierchia 1998. (Another approach could rely on Krifka 2004). Crnic observes that, in contrast to most, most of the is a plu$\mathrm{ral} / \mathrm{mass}$ quantifier and has the full range of readings expected.

Important to us, however, is that while Matthewson's (2001) insight concerning all and most being modifiers of bare plurals in English seems enirely correct, it does not automatically fit with the general approach we are pursuing here. Her observation, as well as Crnic's implementation of it, takes most to be an unanalyzed primitive that is more closely allied with all than with other superlatives.

It is interesting to note now that German does not exhibit the same effects as English (65). For example, the following sentence is perfect on the "more than half of the stuff' reading, and count noun examples do not have a generic feel (thanks to Tom Leu and Lucas Champollion for judgments).

$$
\begin{aligned}
& \text { Maria hat den meisten } \\
& \text { Maria has the most } \\
& \text { 'Mary drank most of the coffee' }
\end{aligned}
$$

This is exactly what Hackl 2009 predicts. One might think that German, a language in which the same phrase corresponds to the absolute and the relative readings, is regular, and the fact that English most combines with bare plurals is an extra complication that should be accounted for separately.

Unfortunately, this cannot be the full story. As has been mentioned above, the Hungarian amount superlative ( $a$ legtöbb) is like German die/den meisten in that the same string supports the absolute and relative readings. But Hungarian $a$ legtöbb exhibits the same effects as English most and the most do in (65)-(66). On the absolute reading a legtöbb + count noun has the generic flavor that English most + bare plural does, and a legtöbb + mass noun lacks an absolute reading in the same way English most + mass noun does. In fact, Hungarian entirely lacks the counterpart of most of the. Like many other languages, it can only express the non-generic proportional reading using the phrase $a(\mathrm{z}) X$ (leg)nagyobb része 'the bigger/biggest part of $X^{\prime}$. Hungarian also replicates English in that comparatives and relative superlatives pattern together and work across the board. For further data and discussion, see Szabolcsi 2012.

In sum, despite the superficial similarity with German and the lack thereof 
Compositionality without word boundaries

with English, interpretation in Hungarian amount superlatives aligns with interpretation in English amount superlatives. Possibly, the solution to the Englishinternal and the cross-linguistic puzzle will be related to what senses of abstract many superlatives are built from. Compositionality does not demand that the same elements be used everywhere, only that reasonably justified elements be used. Following the literature we have used the cardinal interpretation, d-many. But Kotek et al. (2012), for example, explore how the proportional reading of many may be at work in some occurrences of most. Hopefully, these puzzles will teach us something about how to pursue word-internal compositionality.

\section{References}

Aihara, Masahiko. 2009. The scope of -est: evidence from Japanese. Natural Language Semantics 17: 341-367

Barker, Chris. 2007. Parasitic scope. Linguistics and Philosophy 30: 407-444.

Beck, Sigrid. 2011. Lucinda is driving too fast again - the scalar properties of ambiguous than-clauses. To appear in Journal of Semantics.

Bobaljik, Jonathan. 2012. Universals in Comparative Morphology. Cambridge: The MIT Press.

Champollion, Lucas \& Uli Sauerland. 2010. Move and accommodate: a solution to Haddock's puzzle. In Olivier Bonami \& Patricia Cabredo Hofherr (eds.), Empirical Issues in Syntax and Semantics 8, 27-53. Available at http://www.cssp.cnrs.fr/eiss8 .

Chierchia, Gennaro. 1998. Reference to kinds across languages. Natural Language Semantics 6: 339-405.

Cinque, Guglielmo. 2010. The Syntax of Adjectives. Cambridge: The MIT Press.

Cresti, Diana. 1995. Extraction and reconstruction. Natural Language Semantics 3: 79-122.

Crnic, Luka. 2009. On the (non-)cumulativity of cumulative quantifiers. In Martin Prinzhorn, Viola Schmitt, \& Sarah Zobel (eds.), Proceedings of Sinn und Bedeutung 14, 117-133. Available at http://www.univie.ac.at/sub14/proc/crnic.pdf .

Dekker, Paul. 1993. Existential disclosure. Linguistics and Philosophy 16: 561587.

Embick, David. 2010. Localism vs Globalism in Morphology and Phonology. Cambridge: The MIT Press.

Farkas, Donka \& Katalin É. Kiss. 2000. Comparative and absolute readings of superlatives. Natural Language and Linguistic Theory 18: 417-455.

Hackl, Martin. 2009. On the grammar and processing of proportional quantifiers: most versus more than half. Natural Language Semantics 17: 63-98. 
Halle, Morris \& Alec Marantz. 1994. Some key features of Distributed Morphology. In MIT Working Papers in Linguistics 21: 275-288.

Harley, Heidi. 2012. Semantics in Distributed Morphology. In Claudia Maienborn, Paul Portner \& Klaus von Heusinger, (eds.), Semantics: International Handbook of Meaning, Vol. 3. Berlin: de Gruyter.

Heim, Irene. 1985. Notes on comparatives and related matters. Ms., UT Austin. Available at http://semanticsarchive.net/Archive/zc0ZjY0M/ .

Heim, Irene. 1999. Notes on superlatives. Ms., MIT. Available at http://semanticsarchive.net/Archive/TI1MTlhZ/.

Heim, Irene. 2000. Degree operators and scope. In Brendan Jackson and Tanya Matthews (eds.), Proceedings of SALT 10, 40-64. Ithaca: Cornell University. Available at http://elanguage.net/journals/salt/issue/view/293 .

Heim, Irene. 2006. Remarks on comparative clauses as generalized quantifiers. Ms., MIT. Available at http://semanticsarchive.net/Archive/mJiMDBIN/ .

Julien, Marit. 2002. Syntactic Heads and Word Formation. Oxford: Oxford University Press.

Kayne, Richard. 2005. Movement and Silence. Oxford: Oxford University Press.

Kayne, Richard. 2010. Comparisons and Contrasts. Oxford: Oxford University Press.

Koopman, Hilda. 2005. Korean (and Japanese) morphology from a syntactic perspective. Linguistic Inquiry 36: 601-633.

Koopman, Hilda \& Anna Szabolcsi. 2000. Verbal Complexes. Cambridge: The MIT Press.

Kotek, Hadas, Yasutada Sudo, \& Martin Hackl. 2012. 'Many' readings of 'most'. Poster presented at Semantics and Linguistic Theory 22, University of Chicago.

Krasikova, Sveta. 2011. Definiteness in superlatives. In 18th Amsterdam Colloquium Pre-proceedings, 404-414. Amsterdam: ILLC. Available at http://www.illc.uva.nl/AC/AC2011/Proceedings/.

Krasikova, Sveta. 2012. Definiteness in superlatives. In Maria Aloni, Vadim Kimmelman, Floris Roelofsen, Galit W. Sassoon, Katrin Schulz, \& Matthijs Westera (eds.), Logic, Language and Meaning. Lecture Notes in Computer Science, Volume 7218/2012, 411-420. Dordrecht: Springer.

Krifka, Manfred. 2004. Bare NPs: Kind-referring, indefinites, both, or neither? In Robert B. Young \& Yuping Zhou (eds.), Proceedings of SALT 13, 180-203. Available at http://elanguage.net/journals/salt/issue/view/296 .

Larson, Richard. 1988. Scope and comparatives. Linguistics and Philosophy 11: $1-26$.

Lidz, Jeffrey, Justin Halberda, Paul Pietroski \& Tim Hunter. 2011. Interface transparency and the psychosemantics of most. Natural Language Semantics 19: $227-256$. 
Compositionality without word boundaries

Lønning, Jan Tore. 1987. Mass terms and quantification. Linguistics and Philosophy 10: 1-52.

Nakanishi, Kimiko \& Maribel Romero. 2004. Two constructions with most and their semantic properties. In Keir Moulton \& Matthew Wolf (eds.), Proceedings of NELS 34, 453-467.

Matthewson, Lisa. 2001. Quantification and the nature of cross-linguistic variation. Natural Language Semantics 9: 145-189.

Rooth, Mats. 1985. A Theory of Focus Interpretation. PhD dissertation, UMass, Amherst.

Sharvit, Yael \& Penka Stateva. 2002. Superlative expressions, context, and focus, Linguistics and Philosophy 25: 453-504.

Sigurðsson, Halldór Ármann. 2004. The syntax of person, tense, and speech, Rivista di Linguistica 16: 219-251.

Solomon, Mike. 2009. Partitives and the semantics of same. Paper presented at Sinn und Bedeutung 14. Available at http://semanticsarchive.net/Archive/DhhNTdmM/ .

Starke, Michal. 2009. Nanosyntax: a short primer to a new approach to language. Ms., University of Tromsoe. Available at http://ling.auf.net/lingBuzz/001230 .

Stateva, Penka. 2004. Superlative more. In Robert B. Young \& Yuping Zhou (eds.), Proceedings of SALT 13, 276-291. Available at http://elanguage.net/journals/salt/issue/view/296 .

Szabolcsi, Anna 1986. Comparative superlatives. In MIT Working Papers in Linguistics 8: 245-266. Available at http://semanticsarchive.net/Archive/mNlMGYzM/ .

Szabolcsi, Anna. 1997. Strategies for scope taking. In Anna Szabolcsi (ed.), Ways of Scope Taking, 109-155. Dordrecht: Kluwer.

Szabolcsi, Anna. 2010. Quantification. Cambridge: Cambridge University Press.

Szabolcsi, Anna. 2012. Word-less compositionality: case studies in quantification. Colloquium at UCLA, 2-24-2012. Slides available at https://files.nyu.edu/as109/public/szabolcsi word-less ucla.pdf.

Szabolcsi, Anna, James Doh Whang, \& Vera Zu. 2012. Compositionality questions: quantifier words and their multi-functional(?) parts. Ms., New York University. Available at http://semanticsarchive.net/Archive/WVhNmM5Z/ .

Anna Szabolcsi

Department of Linguistics

New York University

10 Washington Place

New York, NY 10003

as109@,nyu.edu 